\title{
A Critique on the Under-explored Sustainable Building Materials in India
}

\author{
Beena Kumari ${ }^{1}$, Pappal Suneja ${ }^{2}$ \\ ${ }^{1}$ (Research Scholar, Department of Civil Engineering, Thapar University, Patiala, India) \\ ${ }_{2}^{2}$ (Department of Architecture, Guru Nanak Dev. University, Amritsar, India) \\ ('bmvashisht@gmail.com, ${ }^{2}$ pappalsuneja@gmail.com)
}

\begin{abstract}
The need of the hour demands that requirements of modern era must be kept in mind, but at the same time celebration of our old traditional past whereby emphasizing on the importance of local materials that are environment friendly should be the main focus. Celebration of our beautiful glorious past could also be initiated by learning from our mistakes and moving ahead towards journey of introspections of what our ancestors did in ancient times and what is intended to be created today. Since, excess of everything is bad, thus variations should be brought up in our approach, whether it is usage of building materials or the certain techniques that are mandatorily followed blindly considering them as standards. Building Materials are an integral part of the building industry, thus in order to achieve the optimum balance between environment and our aspirations; study of the un-explored/under-explored building materials like bamboo, fly ash bricks, various concretes made by using recycled waste materials is important. This paper shall focus on the considerations and accessibility of the under-explored sustainable building materials which may replace the existing materials used in abundance in the construction industry.
\end{abstract}

Keywords - environment friendly, introspection, recycled concrete, sustainable, under-explored.

\section{INTRODUCTION}

Sustainability requires the engineers to consider a building's total cost extended over the useful lifetime. This includes all the expenditure occurred during the construction, maintenance, demolition, and recycling of building [1]. A sustainable structure is one that is constructed in such a manner that the total impact on society during its full life span is negligible. Designing for sustainability means that all the short-term and long-term consequences are considered in the design, regarding the impact on society, considering durability as a key issue [2] [3].

Further, Cement usually has being considered as a by-product satisfying human needs since ages but its high cost lead to its use as a substitute for a long time. But as the time passed, its abundant manufacturing did not only made us dependent on it for the construction purposes but has also adversely affected the environment by the carbon footprints cement manufacturing has left and does intend to exaggerate the situation as the time shall pass by. On the other hand, houses built with traditional materials have gone synonymous with houses for the ones who can't afford, but we have forgotten the un-exploration factor to translate traditional construction and newer sustainable practices into very much attracted and structurally stable constructions. This challenge compels us to look for Environmental Sustainability and thus primarily upon the sustainable building materials. The major factor in contribution of the carbon free environment shall be to reduce energy intensity and hence, reduction on cost with double aspirations namely less environmental hazards and reduced financial implications.

\section{Traditional BUILding Materials}

A far better approach corresponding to use of Traditional and renewable materials for constructing a building involves use of Mud Masonry at boundary walls or parapets, use of terracotta tiles over brickbat/rammed laterite soil for flooring, use of mangalore tiles or earthen pots in roof slabs reducing the amount of reinforcement required as the concrete below the neutral axis being redundant is replaced by these filler materials. Further, the great natural importance of renewable building material bamboo is that it uses practically no energy thus, certain types of bamboo that have the same tensile strength as Tor steel can be used for 
reinforcement instead of steel thus lowering the cost of construction to a significant amount and also contributing to optimize the use of available resources.

There are a lot of bamboo varieties available in our nation. Out of them, few are widely used in construction namely Dendro Calamus Stocksii (Solid), Thrysostachys Oliverii (Lathi), Dendro Calamus Strictus (Kallan), Guada (Straight), Bamboosa Bam (Ordinary Nadan, Mullumola), Bambusa Balcooa (Thronless) and Dendro Calamus (Sikkimensis). Use of bamboo is advantageous as it has a little more tensile strength than tor steel. Thus, it can be efficiently used to cast slab or foundation with bamboo reinforcement. The only trouble comes when the durability of the same is under consideration, as without adequate treatment bamboo construction last not more than 10-15 years because of attack from bore/white ants. So, to treat it the best solution is use of natural reagents borax and boric acid in the ratio $2: 3 \mathrm{~kg}+45$ litre of water in order to make 50 $\mathrm{kg}$ solution. Other method could be use of Copper Sulphate solution immediately after cutting it (this may be not possible usually). Further, since outer layer of bamboo is $100 \%$ water proof; for the above treatment to be successful, we should draw holes through and through nodes of the bamboo. On keeping bamboo (12ft long poles for easy handling) with the chemical mentioned for $48 \mathrm{hrs}$, Osmosis shall take place with Sap content coming up and chem. solution being converted into crystals inside.

\section{BAMBOO BEAMS:}

They can be constructed either by connecting two bamboos together via bolts that is 4 "' +4 " thick for maximum span of 3.5 meters or if the span goes beyond $3.5 \mathrm{~m}$ and upto $4.5 \mathrm{~m}$ use of three bamboos crafted as a triangular beam with through and through bolts. In order to achieve reduced spans bamboo beams may be separated in different sections. The only consideration to be taken care of is that gap between the bamboos connected must be as less as possible.

\section{BAMBOO FOUNDATION:}

They can be used in foundation as bamboo flat cut friction piles (for bridges and multistoried structures) which may be erected upto $15 \mathrm{~cm}$ of lower level of water. In this case bamboo must be well treated as mentioned above to avoid bore attack and it must be well compacted to increase the bearing capacity of the soil in which it is embedded. Bamboo piles must be at least 1 feet apart to avoid unnecessary frictional characteristics and most importantly, bamboo piling should be avoided in case of black cotton soil as it won't sustain much longer. Further, bamboo reinforcement can be used in foundations in a trapezoidal course and use of lime concrete in the ratio 1.5:3:6 with foundation bed of $45 \times 15 \mathrm{~cm}$.

LIME:

Use of lime for wall and roof finishes rather than cement is beneficial especially for a country like India as we are short of energy and lime manufacture uses almost no energy. Cement and lime both are made from calcium found in limestone and shells, these if burnt in a mud kiln by a handful of charcoal to start the burning process results in lime after getting cooled whereas cement is also made from same ingredients including some other items but it requires a lot of fuel in its processing and the ultimate strength of the mortar is the same for both cement and lime.

\section{MUd STABILIZED CONSTRUCTION: RAMMED EARTH}

Rammed earth is a traditional mud construction technique known in Europe, china etc. since ages. It consists of using a mould with two parallel boards to compact the earth inside them such that in situ wall construction is achieved. The traditional technique involves the use of plain earth with adequate sand content. For Instance, there are buildings which are nearly 300 years old and still intact. In this traditional technique, wooden moulds are used with manual ramming using different types of rammers. The equipments are of two types. Firstly, a mould is needed to shape the wall block. Secondly, rammers are used to compact the soil inside the mould.

Further, Soil characteristics vary depending upon the nature of parent rock and type of climatic influences at a particular site. Soils, consists mainly of three types of particles. Namely sand (grains varying in size from $0.075 \mathrm{~mm}$ to $2.0 \mathrm{~mm}$ and chemically inert), Silt (finer sand ranging in size from 0.002 to $0.075 \mathrm{~mm}$ ), Clay (particles finer than $0.002 \mathrm{~mm}$; chemically product of weathering of feldspar) [4]. 


\section{SUSTAINABILITY IN CONTEXT WITH CONCRETE}

Concrete is one of the most widely used construction materials in the world. It is an environmental friendly material and its overall impact on the environment per ton of concrete is limited though its constituent materials don't satisfy the definition of sustainability. It has been observed that in the production of Portland cement, a. indispensable constituent of concrete, 0.9 tons of Carbon dioxide, a greenhouse gas is produced per ton of cement. This implies that Environmental issues will play a pivotal role in the sustainable development of this industry in coming future. The limestone which is a resource to produce cement is running out of whole geographical regions. For fulfilling the requirement of another constituent material of concrete i.e. fine and coarse aggregates, natural resources are being exploited badly. They are also running out of source in many metropolitan areas and it is predicted to happen in some places, that production of Portland cement will not be possible or badly affected, leading a big crisis in the production of concrete. As a result, the whole concrete industry will run out-of-business leaving its many employees jobless.

\section{GREEN CONCRETE}

In this scenario, Green concrete has emerged as an innovative topic which has attracted the focus of engineers, researchers and even the industrialists related to the concrete industry. The concrete made with ecofriendly wastes, is called Green concrete. Green concrete is a concept of using eco-friendly materials in concrete, to make the system more sustainable. Green concrete is economical to produce because waste materials are utilized as a partial replacement for cement leaving reduction of expenditure involved for the disposal of wastes, saving energy consumed in production and increasing durability at the same time.

Variety of by product materials like fly ash, query dust, marble powder/ granules, plastic waste, demolished concrete and masonry are used in the making of green concrete. Further, fly ash and micro silica are being used as replacement of cement to develop new green cements and binding materials. The increased use of alternative raw materials helps in the low energy consumption. Significant research has been carried out on the use of various industrial by-products and micro-fillers in concrete [5]. The cost effectiveness is not only the main motivation of using pozzolanic wastes but to improve certain properties of concrete, mainly durability and to improve the environmental responsiveness of concrete, are the other reasons which make it suitable as a "Green Building" material. Portland cement is being effectively replaced by industrial waste/by products, like fly ash, ground granulated blast slag and silica fume. Efforts are also being done in the direction to use suitable recycled materials as substitutes for concrete aggregate. Recycled concrete aggregate is being tried as course aggregate solving the problem of disposal of the demolished concrete also.

Thus, the use of green concrete is a step towards eco-friendly construction technique. The green concrete is an outstanding substituent of concrete with its remarkable qualities. It is cheaper because it uses waste products and saves energy consumption during the production. It helps to reduce environmental pollution. At the same time, green concrete exhibits greater strength and durability than the normal concrete.

Material Selection Criteria: The general material selection criterion has been covered in the following subheads [6]: -

- Resource Efficiency: It basically includes properties like recycled content, natural or renewable, resource efficient manufacturing process, locally available, salvaged or remanufactured, reusable or recyclable and durability.

- Energy Efficiency: This mainly refers to the energy used for making the concrete. Those materials are preferred that require the minimal amount of energy at the time of construction of the concrete e.g. fly ash helps in the reduction of greenhouse emissions which has a harmful impacts on the economy.

- Water Conservation: Materials that help us and conserve water in landscaped areas are preferred to be used as construction save water at the time of construction or even help reduce water consumption in building materials e.g. use of fly ash decrease the need of water required for hydration process of concrete.

- Affordability: Affordability is one of the major points to be considered when building product lifecycle costs are comparable to traditional materials. 
- Indoor Air Quality: Utilization of materials which are low or non-toxic, have a minor chemical emission and are moisture resistant, help to maintain indoor air quality.

Substituent Materials to Cementitious Materials

Portland cement is not an environmentally friendly material as a considerable amount of Carbon dioxide; a greenhouse gas is produced during its manufacturing. So as good engineers, its use in concrete must be reduced by using more blended cements, especially with chemical admixtures [7].

a) Fly Ash: It is a by-product of the combustion coal in thermal plants. When pulverized coal is burnt to generate heat, the residue contains $80 \%$ slagged particles and unburned carbon known as fly ash and $20 \%$ coarser particles as bottom ash. Fly ash produced in Indian power stations is light-grey in color having the appearance of cement powder. It is a very fine powder which tends to travel far in air. It pollutes air and water and causes respiratory problems when inhaled if not properly discharged in atmosphere and lowers the yield when it settles in fields in the vicinity of the power plant. Use of Fly ash concrete in place of PCC will not only enable substantial savings in the consumption of cement and energy but also provide economy. The use of fly ash has a many advantages. $100 \%$ of Portland cement can be replaced by fly ash theoretically, but replacement levels above $80 \%$ generally have need of a chemical activator. Studies have found that the optimal replacement level of cement by fly ash is around 30\%. Furthermore, fly ash improves certain properties of concrete. It improves the durability as it generates lesser heat during the process of hydration. This property of concrete is specially required for mass concrete applications. The optimal use of fly ash in concrete has many technical advantages. It improves the performance of concrete .In green (fresh) state, Fly ash improves the workability of concrete and in hardened state, and the strength and durability of concrete is improved. Use of Fly ash reduces the mixing water requirement due to low level of heat generation in hydration process. Class $\mathrm{F}$ fly ash also helps in controlling alkali-silica reaction.

b) Silica Fume: It is also known as micro-silica. It is a by-product of the production of silicon and silicon alloys. It contains large proportions of extremely fine particles of silicon dioxide. Fresh concrete containing silica fume is more cohesive and with reduced segregation and bleeding as compared with normal concrete. The use of SF has increased significantly in past few years. Among the application of silica fume in cement based materials a wide range of applications is present. It has gained acceptance in large scale projects due to its impact on the properties of hardened concrete like increased compressive strength, and decreased permeability which helps to control corrosion also [8].

c) Blended cements: It has been used for many decades. The production of blended cements involves the inter grinding of clinker with one or more additives; e.g., fly ash, blast furnace slag, silica fume, volcanic ash, in various proportions. The use of blended cements is a particularly attractive choice as the inter-grinding of clinker with other additives helps to a reduction in the energy used. It also directly corresponds to a decrease in carbon dioxide emissions.

d) The Geo-polymer concrete: It is a vital and promising type of green concrete. Krishnan et al (2014) studied the properties of Geopolymer concrete and found that main limitations of fly ash based Geo-polymer concrete are slow setting of concrete at ambient temperature. To avoid heat curing Ground Granulated Blast Furnace Slag (GGBS) powder is added which shows considerable gain in strength. An alkaline liquid is used to react with the Silicon (Si) and Aluminum (Al) in materials such as fly ash and GGBS to produce binders. Because the chemical reaction that takes place in this case is a polymerization process, the term Geo-polymer is used to represent these binders [9].

Substituent Materials to Fine Aggregates

a) Stone crusher waste: The use of alternating materials for sand in construction industry needs consideration with respect to their availability and applicability. The quarry dust is also one amongst other alternative materials. It is a by-product which is produced in the processing of the 
granite stones into the coarse particles of various sizes. It is a non-valuable waste material after the extraction of rocks to form into the particles of size less than $4.75 \mathrm{~mm}$. Quarry dust is made during blasting, crushing, and screening coarse aggregate. It has rough, sharp and angular particles. Their shape causes a gain in strength due to improved interlocking. Sometimes the use of quarry dust results in increased quantity of cement to maintain workability. But at the same time Quarry dust concrete exhibits better sulphate and acid resistance properties due to reduced permeability, in comparison to that of conventional concrete.

b) Foundry sand: It has been reported by Naik \&Kraus 1999 that Foundry sand can be used as a substitution of regular sand up to $45 \%$ by weight; to meet up different requirements of structuralgrade concrete. Its use in concrete may result in a little loss of compressive strength of concrete as it needs more water but it can be balanced by proper proportioning. Concrete of compressive strength of $42 \mathrm{MPa}$ has been produced using up to $45 \%$ foundry sand as replacement of regular sand [10].

c) Foundry slag: During the pulverization of coal, the coarser particles which fall in the bottom of the furnace, are collected as bottom ash or boiler slag. Foundry slag is suitable for use as a semilightweight coarse aggregate in cement-based materials and it has been used as replacement of aggregate in manufacturing of structural-grade concrete [10].

d) Post-consumer glass: Crushed glass is material which is extremely reactive with cement. Naik $\& W u 2001$ used Ground waste glass as aggregate for mortars and detected that there was no reaction with particle size up to $100 \mu \mathrm{m}$. The results indicated the viability of the reuse of waste glass as substitute of fine aggregate in mortars and concrete. The use of waste glass positively improves the mortar properties and evidently improvising its mechanical performance [11].

e) Wood ash: Wood ash is the residual material, generated owing to burning of wood, and waste from various manufacturing mills such as pulp mills, saw mills, and wood products manufacturing plants. It is composed of both inorganic and organic compounds. Researchers have established Wood fly ash a potential material to be used as a pozzolanic mineral admixture. It can be used as an activator in cement-based materials [12]. Wood ash has been used for various purposes e.g. in the making of structural-grade concrete, bricks/blocks/paving stones, flow able slurry, and blended cements [13].

\section{Substituent Materials of Coarse Aggregates}

a) Recycled Concrete: The efficient disposal of wastes from demolished buildings without harming environment can be a big problem in the present perspective of increasing waste production from building industry. The recycled materials from demolished concrete or masonry can be intelligently and profitably utilized in different ways in the building industry itself. These materials are mostly being used untreated for trench filling, roadbeds, or floor foundation. The wastes from building demolition can be used ambitiously after the proper treatment. Many researchers have tried to explore the possibility of using recycled aggregates to make structural concretes.

b) Recycled Masonry: The wastes material obtained from demolished masonry buildings contains small quantities of bricks, gravel, crushed rock or other forms of stony material as blended material. They can be used as graded coarse aggregates which is produced from clean waste masonry and used for making concretes.

Marble waste as admixture

Marble is a commonly used as a flooring and cladding material since ancient times. Disposal of the waste consisting of very fine powders from the marble industry is again one of the worldwide environmental problems at present. These waste materials can be effectively and economically used as admixtures which improve certain properties of plastic and hardened mortar and concrete.

Waste Plastic as Concrete Composite

Plastic is a material that is manufactured for different applications like product packaging, various house hold items like plastic glasses, bottles, mugs, plastic furniture's, plastic utensils and plastic auto parts etc. 
This cheap flexible and strong material is unfortunately non-biodegradable waste material whose disposal is becoming threat. Plastics can be divided into two types: thermoplastic and thermosetting plastics. The first type is thermoplastic which can be melted for recycling in the plastic industry. The other type is thermosetting plastic which cannot be melted by heating [14]. These plastic types are known as phenolic, melamine, unsaturated polyester, epoxy resin, silicone, and polyurethane. At present, these plastic wastes are disposed by either burning or burying, which are costly processes.

Rebeiz (1996) studied the strength properties of un-reinforced and reinforced polymer concrete using resins based recycled thermoplastic waste. They concluded that resin based recycled thermoplastic waste can be used to make a good quality of precast concrete [15].

\section{SCOPE OF GREEN CONCRETE IN STRUCTURES}

There are several factors which establish the suitability of green concrete in structures which further enhance its scope. Few of these factors are listed below:-

- Reduction of the dead weight of a structure allows easy handling, lifting flexibility due to lighter weight. Reduction of dead weight means slender sections which further leads to reduced size of foundations which means cost cutting.

- Good sound insulation, thermal and fire resistance than the conventional granite rock.

- Impervious concrete stops ingression of water. It makes the building dampness resistant. Additionally it controls corrosion which is a common cause of degradation of structures.

- Increase in speed of construction shortens overall construction period which indirectly results in cost cutting.

- $30 \%$ reduction of $\mathrm{CO}_{2}$-emission created during the manufacturing of cement and concrete industry remarkably controls environmental degradation.

- Green concrete requires less maintenance and repairs.

- Increased use of waste products in concrete industry.

- Green concrete sometimes give better workability than conventional concrete.

- Flexural strength and Compressive strength of concrete is more than that of conventional concrete.

- Most of the Green concretes require lesser curing due to lesser heat production during hydration process.

\section{CONCLUSION}

It is Important to note that all throughout this study the focus relied primarily upon un-explored/underexplored Sustainable building materials. The choice of building material makes a huge difference in our approach towards construction activities. To achieve proximity factor in our approach, materials must be procured within $5 \mathrm{Km}$ of the construction place (Think Globally, Act Locally; As rightly said by our National leader Mahatma Gandhi) and further visual appreciation can be fulfilled by considering both cultural and economic factors hand in hand. The contextual response to understand the site requirements and conceive spaces while bringing in versatility with the use of unexplored sustainable building materials could be the simplest way to not only save on embodied energy nut also think to reduce energy consumption as far as its operational cost id concerned. Hence, our motto should be to adopt use of traditional, technological, economic and social implications while considering the use of materials for construction.

Further, the key challenge faced today is celebration of our traditional past while enhancing the importance of local materials that are environment friendly. This beautiful and glorious past can be celebrated by introspecting the past, learning from the mistakes, from the misleading and rapid movement towards modernity neglecting the splendid knowledge of our ancestors. And based on this, proper steps must be taken for the conservation and rejuvenation of use of our traditional materials. With architecture at heart, emotions rule our head while intellect plays its part. Therefore, focus should be on leaving our footprints in the right places in an appropriate way.

Lastly, considering the Scope of Green Concrete in India- 
As green concrete is made with waste materials it has full scope in India because of industries having problem to dispose wastes. Efficient disposal of waste from demolished buildings is also an issue. Both these issues are addressed by green concrete and at the same time it reduces environmental impact by reducing the emission of Carbon dioxide. Use of green concrete can help us reduce a lot of wastage of several products as various non-biodegradable products can also be used avoiding the issues of their disposal.

\section{REFERENCES}

[1] White paper from the ACI board advisory committee on "Sustainable Development", Farmington Hills, MI, USA: American Concrete Institute, 2004

[2] L. Coppola, S. Monosi, S. Sandri and A. Borsoi, "Recycling of demolished R.C. and P.R.C. structures to manufacture new concrete", L'Industria Italiana del Cemento 705, 1995, 715-728.

[3] V. M. Malhotra, "Fly ash, blast-furnace slag, silica fume and highly reactive metakaolin", Concrete construction handbook (Boca Raton, FL, USA: CRC Press, 1997).

[4] K.S. Jagadish, "Building with Stabilized Mud" (New Delhi: I.K. International Publishing House Pvt. Ltd, 2007).

[5] S. K. Agarwal and D. Gulati, "Utilization of industrial wastes and unprocessed micro-fillers for making cost effective mortars," Construction and Building Materials, 20(10), 2006, 999-1004.

[6] C. Garg and A. Jain, "Green Concrete: Efficient \& Eco-friendly Construction Materials" International Journal of Research in Engineering \& Technology, 2(2), 2014, 259-264.

[7] V.M. Malhotra, "Role of supplementary cementing materials and super plasticizers in reducing greenhouse gas emissions", Fiber composites, high-performance concrete, and smart materials; Proc. ICFRC Int. Conf. on Fiber Composites, High Performance Concretes and Smart Materials, Chennai, India, 489 - 499, 2004.

[8] R. Siddique, Special Structural Concretes (New Delhi: Galgotia Publications Pvt. Ltd., 2000).

[9] L. Krishnan, S. Karthikeyan, S. Nathiya, K. Suganya, "Geopolymer concrete an eco-friendly construction material", International Journal of Research in Engineering and Technology, 03(11), 2014.

[10] T.R. Naik and R.N. Kraus, "The role of flow able slurry in sustainable developments in civil engineering", Materials and construction exploring the connection; Proc. ASCE conf., Cincinnati, USA: American Society of Civil Engineers, 1999.

[11] T.R. Naik and Z. Wu, "Crushed post-consumer glass as partial replacement of sand in concrete, recent advances in concrete technology"; Proc. $5^{\text {th }}$ Int. Conf. CANMET/ACI., Singapore, 200, 2001, 553-568.

[12] T.R. Naik and R.N. Kraus, "A new source of pozzolanic material". Concrete International, Farmington Hills, MI, USA: American Concrete Institute. 25(12), 55-62, 2003

[13] L. Coppola, T. Cerulli and Salvioni, "Sustainable development and durability of self-compacting concretes", V.M. Malhotra, Fly ash, silica fume, slag and natural pozzolans in concrete; Proc. $8^{\text {th }}$ Int. Conf., CANMET/ACI Las Vegas, NV, USA, Publication SPFarmington Hills, MI, USA: American Concrete Institute, 221, 2004, 29-50.

[14] P. Panyakapo and M. Panyakapo, "Reuse of thermosetting plastic waste for lightweight concrete", Waste Management, 28, 2008, 1581-1588.

[15] K. S. Rebeiz, "Precast use of polymer concrete using unsaturated polyester resin based on recycled PET waste", Construction and Building Materials, 10 (3), 1996, 215-220

\section{REFERRED READINGS}

[16] Bhatia, Gautam, Laurie Baker: Life, Work \& Writings (New Delhi: Penguin Books India, 1991).

[17] Baker Laurie, Houses: How to Reduce Building Costs (Thrissur: Centre of Science and Technology for Rural Development, 1986). 